\title{
Introduction to the Special Issue on Green Tides in the Yellow Sea
}

Ming-Jiang Zhou ${ }^{\mathrm{a}}$, Dong-Yan Liu ${ }^{\mathrm{b}}$, Donald M. Anderson ${ }^{\mathrm{c}}$, Ivan Valiela ${ }^{\mathrm{d}}$

${ }^{a}$ Key Laboratory of Marine Ecology and Environmental Sciences, Institute of Oceanology, Chinese Academy of Sciences, Qingdao 266071, China

${ }^{\mathrm{b}}$ Laboratory of Coastal Ecology, Yantai Institute of Coastal Zone Research, Chinese Academy of Sciences, Yantai 264003, China

${ }^{\mathbf{c}}$ Woods Hole Oceanographic Institution, Woods Hole, MA 02543-1049, USA

${ }^{\mathrm{d}}$ Marine Biological Laboratory, Woods Hole, MA 02543, USA

* Corresponding author: Ming-Jiang Zhou

Key Laboratory of Marine Ecology and Environmental Sciences, Institute of Oceanology, Chinese Academy of Sciences, Qingdao 266071, P.R. China.

E-mail address: mjzhou@qdio.ac.cn

Tel: +86-532 82898589

Fax: +86-532 82893088

\begin{abstract}
The spectacular massive green tide of Ulva prolifera in the southern Yellow Sea, which has become a recurrent phenomenon in this region over the last 8 years, attracted much attention of scientists and local government. Several mechanisms have been proposed to explain the early development of green tides in the Yellow Sea, but many questions still remain to be answered. Two years after the first occurrence of massive green tide in the Yellow Sea, a project in the National Basic Research Priority Program (973 project) "Succession of Harmful Algal Blooms in the Coastal Waters of China and the Impacts on Marine Ecosystems (CEOHAB II)" supported by the Ministry of Science and Technology of China started to perform comprehensive investigations and studies on the early development of green tides in the western part
\end{abstract}


of the southern Yellow Sea. In this introduction, we review the progress in understanding aspects of green tide dynamics made by researchers working in the region, and highlight remaining questions.

Key words: green tide, Ulva prolifera, Yellow Sea, Subei shoal

\section{Background}

Blooms of fast-growing macroalgae, sometimes referred to as "green tides", have been reported in many coastal areas in recent years (Ye et al., 2011; Smetacek and Zingone, 2013; Liu et al., 2013). Such macroalgal blooms—often associated with coastal eutrophication - frequently are detrimental to water-related human activities, such as tourism and aquaculture, and have multiple deleterious effects on natural ecosystems (Fletcher, 1996; Valiela et al., 1997; Teichberg et al. 2010; Lyons et al., 2014).

In 2007, a green tide was observed for the first time in coastal waters of Qingdao, China. A spectacular massive green tide appeared again in 2008 (Fig. 1), impaired use of beaches in the region, and posed a significant threat to the Olympic sailing events planned at the site. To protect use of beaches in Qingdao, and allow the Olympic events to take place, over 16,000 people were organized to remove the accumulated algae from the beach, and a long boom was deployed off the shore to prevent floating green algae from approaching the coast (Fig. 1). Approximately 600 boats were involved in collecting floating green algae from the sea area surrounding Qingdao, and eventually, more than 1 million tons of green algae were removed from the coast. Despite the intensive efforts in removing accumulated algae, the green tide still significantly damaged the aquaculture industry in that region and led to substantial economic losses (Wang et al., 2012). The green tide recorded during this period was the world's largest macroalgal bloom, in terms of both affected sea area and the biomass it produced (Liu DY et al., 2009, 2010). Since then, it has become a recurrent phenomenon appearing every summer, albeit at different biomass levels and area covered (Xu et al., 2014), within the Yellow Sea (Fig. 2).

The spectacular green tides in the Yellow Sea quickly attracted the attention of 
scientists and local government. A group of scientists was rapidly organized in 2008 to study the mechanisms and impacts of green tides, monitor the events, and devise mitigation strategies. The major macroalgal species involved in the Yellow Sea green tides was soon identified as Enteromorpha prolifera Müller (Chlorophyta, Ulvophyceae), based on morphological features (Zhang et al., 2008; Ding et al., 2009). The morphologically based identification was further supported by molecular biological evidence of the internal transcribed spacer (ITS) sequences of ribosomal rRNA genes and 5S rDNA spacer sequences (Leliaert et al., 2009; Wang et al., 2010; Liu F et al., 2010; Pang et al., 2010; Duan et al., 2012; Shen et al., 2012). Since the genus Enteromorpha had been synonymized into the genus Ulva according to molecular phylogenetic analyses (Hayden et al., 2003), Ulva prolifera has been used in most recent publications to refer to the dominant green tide species. We also adopt that nomenclature for this Special Issue.

Ulva prolifera is an opportunistic bloom-forming species widely distributed around the world (Ye et al., 2012). Bloom-forming U. prolifera in the Yellow Sea have a complex life history, multiple reproduction modes and a high reproductive rate, the important mechanisms supporting the formation of green tides. The bloom-forming $U$. prolifera proliferates rapidly through sexual, asexual, and vegetative reproduction (Lin et al., 2008). A $1 \mathrm{~cm}^{2}$ blade of $U$. prolifera can release up to 6 million spores and 27 million gametes, and $92-97 \%$ of the spores germinate into young seedlings (Zhang et al., 2013). U. prolifera can efficiently take up nutrients, particularly organic forms of nitrogen, and shows extremely high growth rates (Luo et al., 2012). Mean growth rate of $U$. prolifera ranged about $10-20 \%$ per day in coastal waters of Qingdao; maximum growth rate reached $56.2 \%$ per day in an in situ experiment in Subei Shoal (or Subei Bank in some previous studies) along the coast of Jiangsu province. Bloom-forming $U$. prolifera have unique morphological features (highly branched and hollow tubular thalli with monostromatic walls) that allow floating; this, combined with fast nutrient uptake and growth rates, facilitate formation of large-scale green tides.

Ulva prolifera was and is the dominant species responsible for green tides in the 
Yellow Sea (Zhao et al., 2013), but other green algal species are present in the floating green algal canopies, such as Ulva compressa and Ulva pertusa (Duan et al., 2012). Using the ITS sequence of ribosomal rRNA genes, Jiang et al. (2008) demonstrated that floating Ulva in the Yellow Sea clustered into a clade of Ulva linza-procera-prolifera species complex (LPP species complex), an array that differs from the major attached Ulva species along the coast of Qingdao. Therefore they proposed that bloom-forming Ulva did not derive from the local waters in Qingdao. This idea was further supported by comparisons between the floating and attached forms of $U$. prolifera (Wang et al., 2010; Duan et al., 2012).

Remote-sensing of green tides supported the idea of long-distance transport of floating algae. Satellite images, field observations, and physical oceanographic modeling all indicated that floating patches of Ulva prolifera were repeatedly formed in the near-shore water of Jiangsu province (i.e. Subei Shoal, Fig. 3a,b) along the coast of southern Yellow Sea (Sun et al., 2008; Hu, 2009; Liu DY et al., 2009, 2010; Keesing et al., 2011; Qiao et al., 2011; Lee et al., 2011). Therefore, Subei Shoal is a critical area to investigate the mechanisms for the formation and early development of green tides in the Yellow Sea.

Subei Shoal is a unique intertidal mudflat zone with an area around $22,740 \mathrm{~km}^{2}$ (Li, 2011). It extends over $200 \mathrm{~km}$ from the Sheyang River estuary to the Changjiang River estuary, and $90 \mathrm{~km}$ from the shoreline to open sea. Subei Shoal has radial sand ridges at the bottom that create large tidal excursions and strong tidal currents. Many rivers discharge into this shallow water region and input very substantial nutrient loads. The shallow and nutrient-rich water column makes Subei Shoal a propitious environment for cultivation of the commercially important seaweed Porphyra yezoensis (Fig. 3c, d). From the 2000s, the flux of nutrients from the major rivers into Subei Shoal increased significantly (Ma et al., 2010). Rapid expansion of animal aquaculture industry along the coast of Jiangsu Province also discharged large amounts of organic nitrogen into the sea (Pang et al., 2010).

Based on the unique features of the Subei Shoal, several mechanisms have been proposed to explain the early development of green tides in this region. Liu DY et al. 
$(2009,2010)$ and Keesing et al. (2011) suggested that the rapid expansion of Porphyra aquaculture was the major reason for the appearance of large-scale green tides. Several other surveys, however, found none or few Ulva prolifera on the Porphyra rafts (Pang et al., 2010; Shen et al., 2012) and hypothesized that $U$. prolifera might originate from land-based aquaculture ponds, or somatic cells, vegetative fragments and micro-propagules presented in the coastal waters or sediments etc. (Pang et al., 2010; Zhang et al., 2010, 2011; Liu F et al., 2012). There are therefore arguments for different mechanisms for the origin of green tides, as well as many other questions remaining to be answered: How does $U$. prolifera recurrently develop into large-scale green tides in the Yellow Sea? What is the relationship between green tides and eutrophication and aquaculture activities in this region? Why did Subei Shoal become the most important region for the development of green tides in the Yellow Sea? To answer these questions, comprehensive multi-disciplinary investigations, including biological, chemical, ecological and oceanographic studies were needed to cover a sufficiently large area and to collect time-series data concerning the early development of green tides in the Yellow Sea.

In 2009, two years after the first occurrence of massive green tide in the Yellow Sea, a project in the National Basic Research Priority Program (973 project) "Succession of Harmful Algal Blooms in the Coastal Waters of China and the Impacts on Marine Ecosystems (CEOHAB II)" was supported by the Ministry of Science and Technology of China. One of the major tasks of this project was to elucidate the mechanisms and early development processes of green tides in the Yellow Sea. Many cruises to Subei Shoal took place, supporting comprehensive investigations on the western part of the southern Yellow Sea, and monthly investigations in Subei Shoal acquired time-series data in this region (Fig. 4). The major findings of the project, together with recent progresses made by other relevant groups, were compiled to form this Special Issue: "Green tides in the Yellow Sea".

\section{Contributions of the special issue}

Fifteen papers are included in this Special Issue, covering a wide variety of green tide studies, including, among other topics, a rapid method for detection of 
bloom-forming Ulva prolifera, adaptive strategies, physiological and life history features of $U$. prolifera, ecological processes related to onset of green tides, and the relationship between oceanographic conditions of Subei Shoal and the formation of green tides. The papers in the Issue consider new ideas and update current understanding of the dynamics of green tides in the Yellow Sea.

\subsection{Detection, development, and expansion of green tides in the Yellow Sea}

Zhang QC et al. (this issue, a) developed a fluorescence in situ hybridization (FISH) method to detect bloom-forming Ulva prolifera. This method used a specifically-designed probe targeting the $5 \mathrm{~S}$ spacer region of $U$. prolifera, and could rapidly identify $U$. prolifera by fluorescence microscopy and give quantitative estimates of the proportion of $U$. prolifera in a green algal sample. This method makes it possible to perform rapid analyses during the development of $U$. prolifera blooms.

Song et al. (this issue, a), based on time-series investigations from October 2010 to October 2011 in Subei Shoal, documented year-round abundance of green algal propagules in waters and sediments. Variation in abundance and distribution of Ulva propagules in Subei Shoal could be spatially linked to Porphyra cultivation activities in this region. With the FISH method, Zhang QC et al. (this issue, b) further confirmed the presence of Ulva prolifera propagules in Subei Shoal, and confirmed that $U$. prolifera propagules gave rise to the $U$. prolifera population attached to Porphyra culture rafts.

Fan et al. (this issue) analyzed succession of macroalgal species attached to Porphyra culture rafts, and found that the dominant species in the green algal community shifted to Ulva prolifera and Blidingia sp. in mid-May. These results are consistent with results obtained using the FISH method by Zhang QC et al. (this issue, b). In laboratory studies, Song et al. (this issue, b) found that warmer water temperatures in May were associated with germination of green algae propagules and succession in the attached green algal community. These studies also offered strong evidence for the dominant position of Ulva prolifera in the green algal community attached to the Porphyra culture rafts in spring.

Liu et al. (this issue) sampled biomass of floating green algae during four cruises 
from May to June of 2012 to investigate the changes in floating green algal biomass, and trace the expansion of green tide through the southern Yellow Sea. Total biomass of floating algae quickly increased from $~ 2,000$ tons in early May to 364,000 tons in early June. They also found that free-floating patches of green algae dominated by $U$. prolifera were primarily confined to Subei Shoal in early May, and drifted gradually to the southern coast of the Shandong Peninsula in one month. No green algae were found floating into Subei Shoal from other regions of the southern Yellow Sea during the investigations. During this process, U. prolifera were always dominant, and dominance increased gradually during drift (Zhang QC et al., this issue, b).

The bloom-forming Ulva prolifera must be well adapted to changes in light irradiance, particularly at the floating stage. The mechanisms involved in the high NPQ in Ulva were also characterized, using Ulva linza as a model organism (Zhang $\mathrm{XW}$ et al., this issue).

\subsection{Oceanographic characteristics of Subei Shoal and its relationship with green tides}

Bao et al. (this issue) studied trajectories of satellite-tracked surface drifters, and applied an FVCOM model forced by tides and surface winds to define driving forces for movement of floating green algae in Subei Shoal and the southern Yellow Sea. Floating algae were transported by tidal residual currents in the channels between the sand ridges in the shoal. In the southern Yellow Sea, wind became the dominant forcing underlying the drift of floating green algae. Model simulations indicated that particles drifted northward with S-SE winds, a pattern consistent with northward movement of drifters tracked by satellite.

Li et al. (this issue) reviewed the historical patterns of nutrient composition and concentration in Subei Shoal, and reported a gradual increase of DIN and N/P over the last 30 years, particularly after 2008. These apparent increases are closely associated with the increasing input of nitrogen from the Changjiang River and other smaller rivers along the coast of Subei Shoal.

Sun et al. (this issue) found that bloom-forming Ulva prolifera exhibited a rapid increase in uptake rates of both nitrate and phosphate when exposed to high 
concentration of nutrients, and $U$. prolifera could utilize multiple nutrient sources. Shi et al. (this issue) further addressed the importance of land-based nutrient input in the formation of green tides, and reported high concentrations of DON in this region based on the field investigation, which could be used by $U$. prolifera when inorganic $\mathrm{N}$ was depleted.

\subsection{Importance of Porphyra culture rafts in the formation of green tides}

The tidal and hydrodynamic conditions, and land-derived delivery of nutrients taking place in the Yellow Sea, all favor development of the green tides. The actual sources of the propagules that generate the potential green tides seem likely linked to the Porphyra culture rafts deployed in this region. Porphyra culture rafts, including ropes, bamboo poles and nets, offer substantial surfaces for the attachment of green algal propagules that could, helped by parthenogenesis and other features of growth, be the founding sources of fronds that become floating green tides. This could be checked by genomic studies of the attached and floating fronds.

Geng et al. (this issue) found that abundances of green algal propagules attached to the surface of materials used in Porphyra rafts (plastic, bamboo, jute rope, plastic rope, nylon and other netting) were significantly higher than those on natural surfaces (mud, sand, rocks). They concluded that Porphyra rafts must play an important role in the early development of green tides.

Liu et al. (this issue) suggested that parthenogenesis could play an important role in the rapid growth of attached $U$. prolifera populations. Parthenogenetic reproduction is a common feature of bloom-forming $U$. prolifera in the Yellow Sea, and unfertilized gametes could develop into both gametophytes and parthenosporophytes. This is likely to promote rapid proliferation of $U$. prolifera populations and could maintain the unique genetic features of this species.

Zhao et al. (this issue) studied genetic variation and relationships at the intra-species level among floating and $U$. prolifera collected from different substrates in the shores of the Yellow Sea (but not from rafts). They found that floating samples of $U$. prolifera from the Yellow Sea, taken during the past 5 years, were genetically similar and different from non-raft surface attached samples of $U$. prolifera collected 
from the intertidal zone of the Southern Yellow Sea. In agreement with Wang et al. (2010) and Duan et al. (2012), Zhao et al. (this issue) proposed that fronds of floating U. prolifera may derive from a unique ecotype. This finding might suggest that juvenile algae attached to coastal substrates might not be the source of propagules that eventually become floating green tides, and cast some doubt about the notion that coastal maricultural rafts could be involved in green tide origins. There are still unpublished results, obtained using the same methods, that suggest that $U$. prolifera attached on Porphyra culture rafts were genetically the same as floating samples (Zhang QC, unpublished data). These conflicting results suggest that only those germlings attached to rafts give origin to floating green tides, a curious and unlikely prediction. Clearly, more study of these features will be needed.

While much remains to be learned as to the primary origin and mechanisms creating green tides, we can preliminarily argue, with the information presented in this special issue, that early development of green tide in Subei Shoal and the southern Yellow Sea (Fig. 5) may begin as green algal propagules-present year-round in Subei Shoal— that start to germinate and attach, most likely, to Porphyra culture rafts when the rafts are established on Subei Shoal during autumn. The attached propagules grow and gradually dominate the attached green algal community by late April to early May in the following year, as water temperature turns warm (aquaculture rafts act as an "amplifier" that spurs early macroalgal abundance and growth). After the attached green algae are removed from the rafts as the farmers clean them, fragments of fronds of Ulva prolifera become floating (the role of aquaculture rafts now changes to that of a "converter" that releases the originally attached macroalgal fragments into floating form in the sea). The biomass of $U$. prolifera rapidly increases during floating in nutrient-rich surface seawater, supported by the remarkably abundant nutrient supply in Yellow Sea surface waters, and the biomass then drifts widely as a result of residual tidal currents and wind in the Yellow Sea, with the end result being the "world's largest" green tide.

\section{Unknown questions and research perspectives}




\section{Acknowledgements}

We gratefully acknowledge the National Basic Research Priority Project 
(2010CB428700) supported by the Ministry of Science and Technology of China, the Strategic Priority Research Program (XDA11020304) supported by the Chinese Academy of Science, and projects (41121064, U1406403) supported by the National Natural Science Foundation of China. Support for D. M. Anderson was provided through the Woods Hole Center for Oceans and Human Health, National Science Foundation Grant OCE-1314642 and National Institute of Environmental Health Sciences Grant 1-P01-ES021923-01. We deeply appreciate the outstanding efforts of the scientists and crews during the CEOHAB II cruises. Special thanks also to Judith L. Kleindinst, Rencheng Yu, Qingchun Zhang, and officers of ECSS for their significant contributions to the production of this Special Issue.

\section{References}

Bao, M., Guan, W.B., Yang, Y., Cao, Z.Y., Chen, Q., Drifting trajectories of green algae in the western Yellow Sea during spring and summer 2012. Estuarine Coastal and Shelf Science, DOI: 10.1016/j.ecss.2015.02.009, this issue.

Ding, L.P., Luan, R.X., 2009. The taxonomy, habit and distribution of a green alga Enteromorpha prolifera (Ulvales, Chlorophyta). Oceanologia et Limnologia Sinica 40, 68-71 (in Chinese, with English Abstract).

Duan, W.J., Guo, L.X., Sun, D., Zhu, S.F., Chen, X.F, Zhu, W.R., Xu, T., Chen, C.F., 2012. Morphological and molecular characterization of free-floating and attached green macroalgae Ulva spp. in the Yellow Sea of China. Journal of Applied Phycology 24, 97-108.

Fan, S.L., Fu, M.Z., Wang, Z.L., Li, Y., Liu, G.X., Liu, X.Q., Song, W., Wang, X.N., Xaio, J., Zhu, M.Y., Temporal variation of green algae community on Porphyra aquaculture rafts in the Subei Shoal, China. Estuarine Coastal and Shelf Science, DOI: 10.1016/j.ecss.2015.03.016, this issue. 
Fletcher, R.L., 1996. The occurrence of 'green tide'. In: Schramm, W., Nienhuis, P.H. (Eds), Marine Benthic Vegetation-Recent Changes and the Effects of Eutrophication. Springer Verlag, Berlin, pp. 7-43.

Geng, H.X, Yan, T., Zhou, M.J., Liu, Q., Comparative study of the germination of Ulva prolifera gametes on different substrates. Estuarine, Coastal and Shelf Science, DOI: 10.1016/j.ecss.2014.12.026, this issue.

Hayden, H.S., Blomster, J., Maggs, C.A., Silva, P.C., Stanhope, M.J., Waaland, J.R., 2003. Linnaeus was right all along: Ulva and Enteromorpha are not distinct genera. European Journal of Phycology 38, 277-294.

$\mathrm{Hu}, \mathrm{C} ., 2009$. A novel ocean color index to detect floating algae in the global oceans. Remote Sensing of Environment 113, 2118-2129.

Jiang, P., Wang, J. F., Cui, Y. L., Li, Y. X., Lin, H. Z., Qin, S., 2008. Molecular phylogenetic analysis of attached Ulvaceae species and free-floating Enteromorpha from Qingdao coasts in 2007. Chinese Journal of Oceanology and Limnology 26, 276-279.

Keesing, J.K., Liu, D.Y., Fearns, P., Garcia, R., 2011. Inter-and intra-annual patterns of Ulva prolifera green tides in the Yellow Sea during 2007-2009, their origin and relationship to the expansion of coastal seaweed aquaculture in China. Marine Pollution Bulletin 62, 1169-1182.

Lee, J.H., Pang, I.C., Moon, I.J., Ryu, J.H., 2011. On physical factors that controlled the massive green tide occurrence along the southern coast of the Shandong Peninsula in 2008: a numerical study using a particle-tracking experiment. Journal of Geophysical Research116, C12036.

Leliaert, F., Zhang, X., Ye, N., Malta, E.J., Engelen, A.H., Mineur, F., Verbruggen, H., De Clerck, O., 2009. Research note: identity of the Qingdao algal bloom. 
Phycological Research 57, 147-151.

Li, H.M., Zhang, C.S., Han, X.R., Shi, X.Y., The chemical oceanography of biogenic elements in the southern Yellow Sea. Estuarine, Coastal and Shelf Science, DOI: 10.1016/j.ecss.2014.12.013, this issue.

Li, M.G., 2011. Advances in the research and development of the radial sandbanks. Journal of Waterway and Harbor 32, 229-243 (in Chinese, with English abstract).

Lin, A.P., Shen, S.D., Wang, J.W., Yan, B.L., 2008. Reproduction diversity of Enteromorpha prolifera. Journal of Integrative Plant Biology 50, 622-629.

Liu, D.Y., Keesing, J.K., Xing, Q.G., Shi, P., 2009. World's largest macroalgal bloom caused by expansion of seaweed aquaculture in China. Marine Pollution Bulletin $58,888-895$.

Liu, D.Y., Keesing, J.K., Dong, Z.J., Zhen, Y., Di, B.P., Shi, Y.J., Fearns, P., Shi, P., 2010. Recurrence of the world's largest green-tide in 2009 in Yellow Sea, China: Porphyra yezoensis aquaculture rafts confirmed as nursery for macroalgal blooms. Marine Pollution Bulletin 60, 1423-1432.

Liu, D.Y., Keesing, J.K., He, P.M., Wang, Z.L., Shi, Y.J., Wang, Y.J., 2013. The world's largest macroalgal bloom in the Yellow Sea, China: Formation and implications. Estuarine Coastal and Shelf Science. 129, 2-10.

Liu, F., Pang, S.J., Chopin, T., Xu, N., Shan, T.F., Qin, S., Sun, S., 2010. The dominant Ulva strain of the 2008 green algal bloom in the Yellow Sea was not detected in the coastal waters of Qingdao in the following winter. Journal of Applied Phycology 22, 531-540.

Liu, F., Pang, S.J., Zhao, X.B., Hu, C.M., 2012. Quantitative, molecular and growth analyses of Ulva microscopic propagules in the coastal sediment of Jiangsu province where green tides initially occurred. Marine Environmental Research 74, 
56-63.

Liu, Q., Yu, R.C., Yan, T., Zhang, Q.C., Zhou, M.J., Laboratory study on the life history of bloom-forming Ulva prolifera in the Yellow Sea. Estuarine Coastal and Shelf Science, DOI: 10.1016/j.ecss.2014.08.011, this issue.

Liu, X.Q., Li, Y., Wang, Z.L., Zhang, Q.C., Cai, X.Q., Cruise observation of Ulva prolifera bloom in the southern Yellow Sea, China. Estuarine Coastal and Shelf Science, DOI: 10.1016/j.ecss.2014.09.014, this issue.

Luo, M.B., Liu, F., Xu, Z.L., 2012. Growth and nutrient uptake capacity of two co-occurring species, Ulva prolifera and Ulva linza. Aquatic Botany 100, 18-24.

Lyons, D.A., Arvanitidis, C., Blight, A.J., Chatzinikolaou, E., Guy-Haim, T., Kotta, J., Orav-Kotta, H., Queiros, A.M., Rilov, G., Somerfield, P.J., Crowe, T.P.. 2014. Macroalgal blooms alter community structure and primary productivity in marine ecosystems. Global Change Biology 20, 2712-2724.

Ma, H.R., Chen, J.F., Cui, Y., Zhao, J., Ma, S.S., Yang, F., 2010. Analysis of water quality and assessment of major pollutants input to the sea from the Guan River and Sheyang River. Progress in Fishery Sciences 31, $92-99$ (in Chinese, with English abstract).

Pang, S.J., Liu, F., Shan, T.F., Xu, N., Zhang, Z.H., Gao, S.Q., Chopin, T., Sun, S., 2010. Tracking the algal origin of the Ulva bloom in the Yellow Sea by a combination of molecular, morphological and physiological analyses. Marine Environment Research 69, 207-215.

Qiao, F.L., Wang, G.S., Lu, X.G., Dai, D.J., 2011. Drift characteristics of green macroalgae in the Yellow Sea in 2008 and 2010. Chinese Science Bulletin $56,2236-2242$.

Shen, Q., Li, H.Y., Li, Y., Wang, Z.L., Liu, J.S., Yang, W.D., 2012. Molecular 
identification of green algae from the rafts based infrastructure of Porphyra yezoensis. Marine Pollution Bulletin 64, 2077-2082.

Shi, X.Y., Qi, M.Y., Tang, H.J., Han, X.R., Spatial and temporal nutrient variations in the Yellow Sea and theireffects on Ulva prolifera blooms. Estuarine Coastal and Shelf Science, DOI: 10.1016/j.ecss.2015.02.007, this issue.

Smetacek, V., Zingone, A., 2013. Green and golden seaweed tides on the rise. Nature $504,84-88$.

Song, W., Li, Y., Fang, S., Wang, Z.L., Xiao, J., Li, R.X., Fu, M.Z., Zhu, M.Y., Lei, Z.X., Temporal and spatial distributions of green algae micro-propagules in the coastal area of the Subei Shoal, China. Estuarine Coastal and Shelf Science, DOI: 10.1016/j.ecss.2014.08.006, this issue, a.

Song, W., Peng, K.Q., Xiao, J., Li, Y., Wang, Z.L., Liu, X.Q., Fu, M.Z., Fang, S.L., Zhu, M.Y., Li, R.X., Effects of temperature on the germination of green algae micro-propagules in coastal waters of the Subei Shoal, China. Estuarine Coastal and Shelf Science, DOI: 10.1016/j.ecss.2014.08.007, this issue, b.

Sun, K.M., Li, R.X., Li, Y., Xin, M., Wang, Z.L., Tang, X.X., Xiao, J., Pang, M., Rapid responses of Ulva prolifera to nutrient enrichment under light and dark conditions. Estuarine Coastal and Shelf Science, DOI: 10.1016/j.ecss.2015.03.018, this issue.

Sun, S., Wang, F., Li, C. L., Qin, S., Zhou, M. J., Ding, L. P., Pang, S. J., Duan, D. L., Wang, G. C., Yin, B. S., Yu, R. C., Jiang, P., Liu, Z.L., Zhang, G. T., Fei, X. G., Zhou, M., 2008. Emerging challenges: Massive green algae blooms in the Yellow Sea. Nature Precedings, hdl:10101/npre. 2008.2266.1.

Teichberg, M., Fox, S.E., Olsen, Y.S., Valiela, I., Martinetto, P., Iribarne, O., Muto, E.Y., Petti, M.A.V., Corbisier, T.N., Soto-Jimenez, M., Paez-Osuna, F., Castro, P., 
Freitas, H., Zitelli, A., Cardinaletti, M., Tagliapietra, D., 2010. Eutrophication and macroalgal blooms in temperate and tropical coastal waters: nutrient enrichment experiments with Ulva spp. Global Change Biology 16, 2624-2637.

Valiela, I., McClelland, J., Hauxwell, J., Behr, P.J., Hersh, D., Foreman, K., 1997. Macroalgal blooms in shallow estuaries: controls and ecophysiological and ecosystem consequences. Limnology and Oceanography 42, 1105-1118.

Wang, C., Yu, R.C., Zhou, M.J., 2012. Effects of the decomposing green macroalga Ulva (Enteromorpha) prolifera on the growth of four red-tide species. Harmful Algae 16, 12-19.

Wang, J.F., Jiang, P., Cui, Y.L., Li, N., Wang, M.Q., Lin, H.Z., He, P.M., Qin, S., 2010. Molecular analysis of green-tide-forming macroalgae in the Yellow Sea. Aquatic Botany 93, 25-31.

Xu, Q., Zhang, H.Y., Ju, L., Chen, M.X., 2014. Interannual variability of Ulva prolifera blooms in the Yellow Sea, International Journal of Remote Sensing 35, 4099-4113.

Ye, N.H., Zhang, X.W., Mao, Y.Z., Liang, C.W., Xu, D., Zou, J., Zhuang, Z.M., Wang, Q.Y., 2011. 'Green tides' are overwhelming the coastline of our blue planet: taking the world's largest example. Ecological Research 26, 477-485.

Zhang, J.H., Huo, Y.Z., Yu, K.F., Chen, Q.F., He, Q., Han,W., Chen, L.P., Cao, J.C., Shi, D.J., He, P.M., 2013. Growth characteristics and reproductive capability of green tide algae in Rudong coast, China. Journal of Applied Phycology 25, 795-803.

Zhang, Q.C., Liu, Q., Kang, Z.J., Yu, R.C., Yan, T., Zhou, M.J. Development of a fluorescence in situ hybridization method for rapid detection of Ulva (Enteromorpha) prolifera. Estuarine, Coastal and Shelf Science, DOI: 
10.1016/j.ecss.2014.09.004, this issue, a.

Zhang, Q.C., Liu, Q., Yu, R.C., Kang, Z.J., Guo, W., Ding, Y.M., Chen, J.H., Wang, Y.F., Li, Y., Yan, T., Zhou, M.J., Application of a fluorescence in situ hybridization (FISH) method to study green tides in the Yellow Sea. Estuarine, Coastal and Shelf Science, DOI: 10.1016/j.ecss.2014.09.005, this issue, b.

Zhang, X.L., Song, Y.J., Liu, D.Y., Kessing, J.K., Gong, J., 2014. Characterization of diazotrophic bacterial community associated with macroalgae bloom in the Yellow Sea, China. Estuarine, Coastal and Shelf Science, DOI:

10.1016/j.ecss.2014.12.015, this issue.

Zhang, X.W., Mao, Y.Z., Zhuang, Z.M., Liu, S.F., Wang, Q.Y., Ye, N.H., 2008. Morphological characteristics and molecular phylogenetic analysis of green tide Enteromorpha sp. occurring in the yellow Sea. Journal of Fishery Sciences of China 15, 822-829 (in Chinese, with English Abstract).

Zhang, X.W., Mou, S.L., Cao, S.N., Fan, X., Xu, D., Ye, N.H., Roles of the transthylakoid proton gradient and xanthophyll cycle in the non-photochemical quenching of the green alga Ulva linza. Estuarine, Coastal and Shelf Science, DOI: 10.1016/j.ecss.2014.09.006, this issue.

Zhang, X.W., Wang, H.X., Mao, Y.Z., Liang, C.W., Zhuang, Z.M., Wang, Q.Y., Ye, N.H., 2010. Somatic cells serve as a potential propagules bank of Enteromorpha prolifera forming a green tide in the Yellow Sea, China. Journal of Applied Phycology 22, 173-180.

Zhang, X.W., Xu, D., Mao, Y.Z., Li, Y.X., Xue, S.Y., Zou, J., Lian, W., Liang, C.W., Zhuang, Z.M., Wang, Q.Y., Ye, N.H., 2011. Settlement of vegetative fragments of Ulva prolifera confirmed as an important seed source for succession of a large-scale green tide bloom. Limnology and Oceanography 56, 233-242. 
Zhao, J., Jiang, P., Liu, Z.Y., Wei, W., Lin, H.Z., Li, F.C., Wang, J.F., Qin, S., 2013. The Yellow Sea green tides were dominated by one species, Ulva (Enteromorpha) prolifera, from 2007 to 2011. Chinese Science Bulletin 58, 2298-2302.

Zhao, J., Jiang, P., Qin, S., Liu, X.J., Liu, Z.Y., Lin, H.Z., Li, F.C., Chen, H.X., Wu, C.H., 2014. Genetic analyses of the Yellow Sea floating Ulva prolifera imply a new ecotype. Estuarine, Coastal and Shelf Science, this issue. 


\section{Figure captions}

Figure 1. Massive green tide appeared in Qingdao (A, B) in 2008. Removal and containment means applied to remove (C), and limit the expansion (D) of the huge amounts of accumulated green algae.

Figure 2. Extent and cover of green tides in the Yellow Sea from 2008 to 2014 (data from the Bulletin of Marine Environmental Status of China, 2008-2014)

Figure 3. Maps of the Yellow Sea (A), Subei Shoal (B) and photos of Porphyra aquaculture rafts located in Subei Shoal (C, D) in which green color indicated the green algae attached on the rafts.

Figure 4. Sampling stations of cruises organized by the 973 project in 2012.

Black dots: stations in 8 transects (da, ga, gb, gc, gd, ge, gf, gg and gh) to investigate the dynamics and distribution of green tides in southern Yellow Sea from Apr. 16 to Jun. 8 in 2012. White triangles: stations in 5 transects (A, B, C, E, F) to investigate the distribution of floating green algae and microscopic propagules in Subei Shoal and their relationship with the raft culture of Porphyra in 2011 and 2012. (Color bar indicates depth, in $\mathrm{m}$, in the map)

Figure 5. A conceptual model of development of green tides in southern Yellow Sea. Green algal propagules, including those of bloom-forming Ulva prolifera, are present around the year in Subei Shoal. After deployment of Porphyra culture rafts in autumn in the Shoal, propagules of $U$. prolifera start to attach to the rafts and gradually dominate the attached green algal community in late April to early May in the following year. The attached green algae are removed from rafts during the process of Porphyra harvesting and became a floating algal canopy. Supported by nutrient-rich seawater in Subei shoal, the floating green algae proliferate rapidly, and move northward driven by the tidal currents and wind, with the end result being the "world's largest" green tide. During this process, the Porphyra culture rafts act as an "amplifier" that spurs early macroalgal abundance and growth, and a "converter" that releases the attached macroalgal fragments into the sea in floating form. 



C D

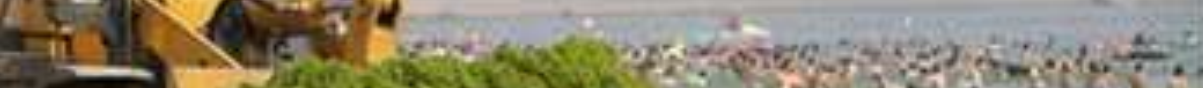

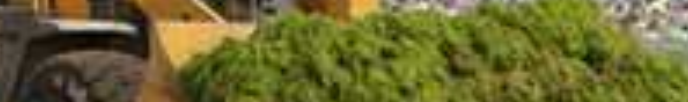
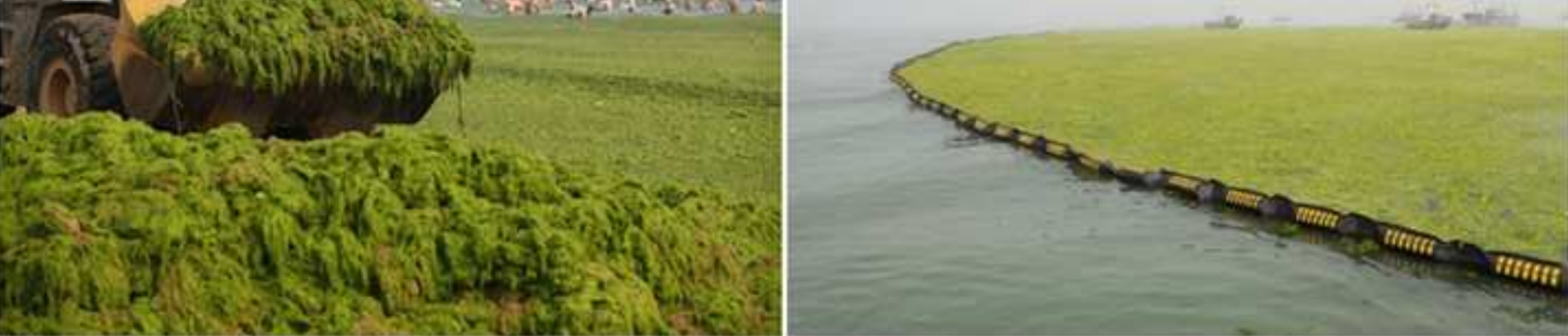


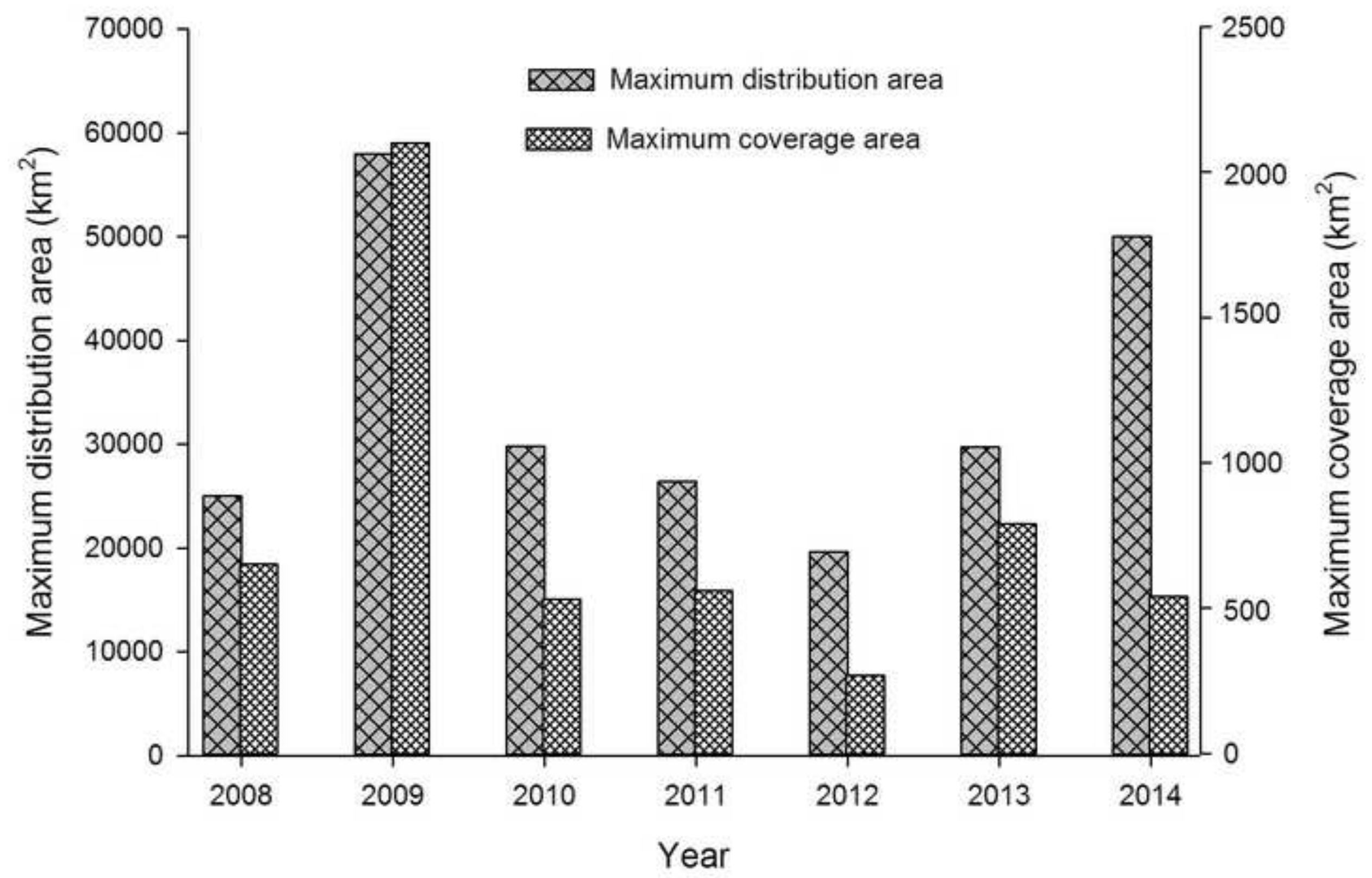



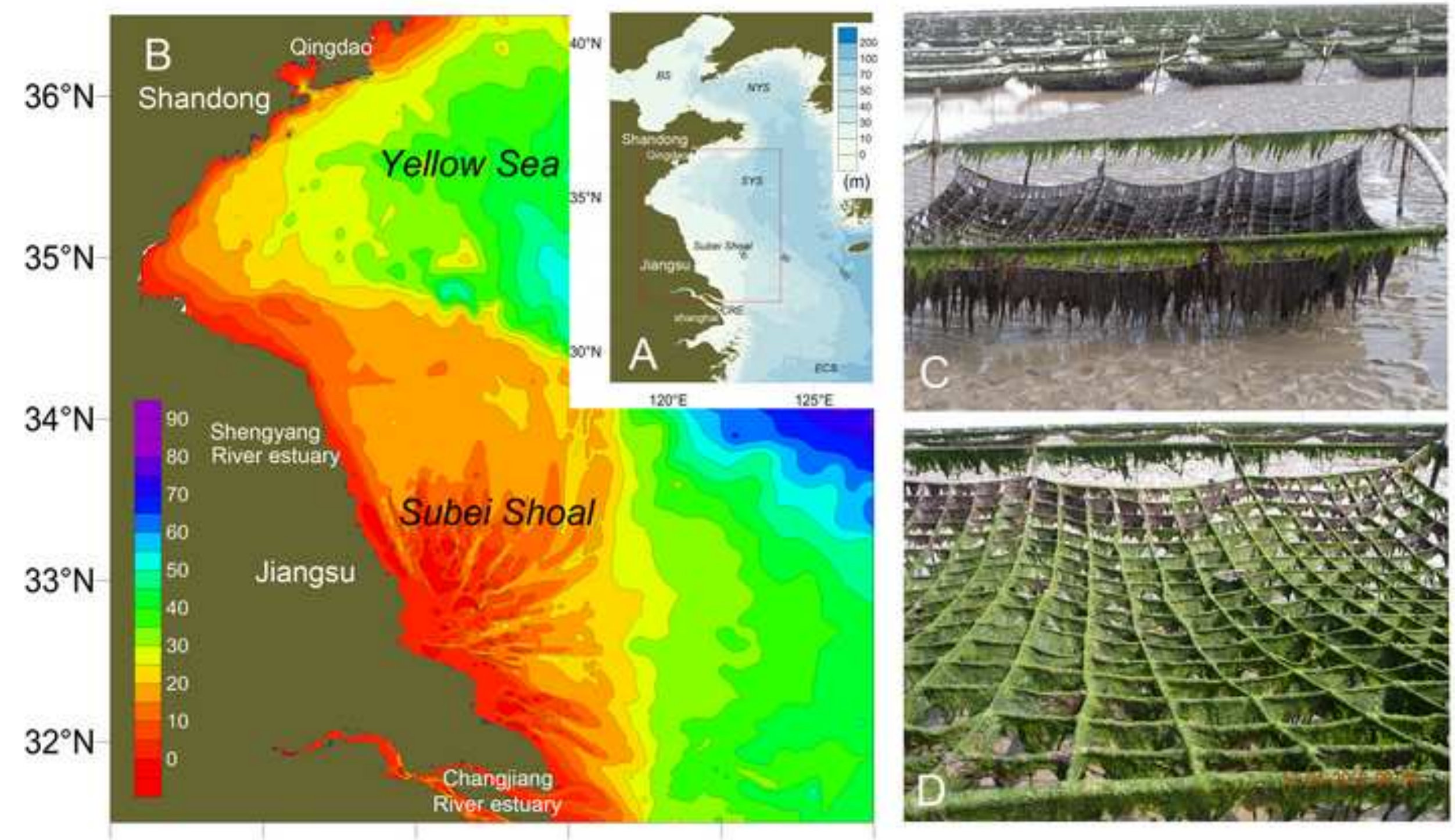

$119^{\circ} \mathrm{E} \quad 120^{\circ} \mathrm{E} \quad 121^{\circ} \mathrm{E} \quad 122^{\circ} \mathrm{E} \quad 123^{\circ} \mathrm{E} \quad 124^{\circ} \mathrm{E}$

119 E $120^{\circ} \mathrm{E}-121^{\circ} \mathrm{E}-122^{\circ} \mathrm{E}-123^{\circ} \mathrm{E}-124^{\circ} \mathrm{E}$









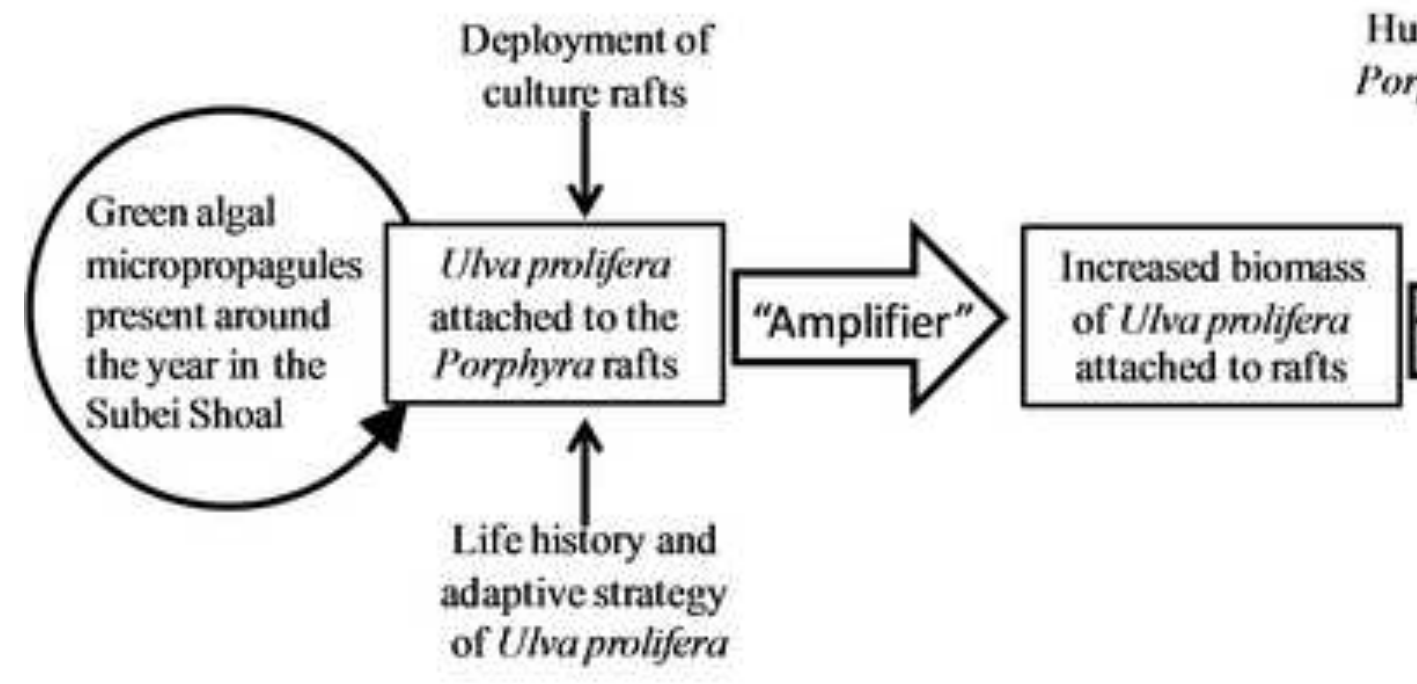

Human activity:

Porphyraharvest

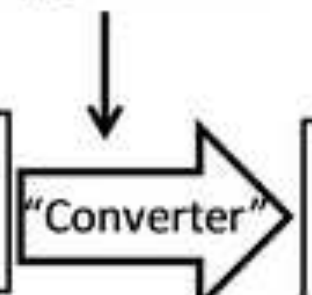

Movement of floating green algae driven by tidal currents and wind

\section{Floating U/va prolifera in the Yellow Sea}

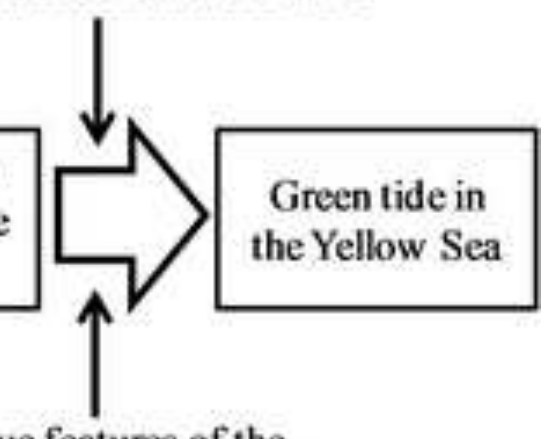

Unique features of the Subei Shoal: strong tide and nutrient-rich seawater 


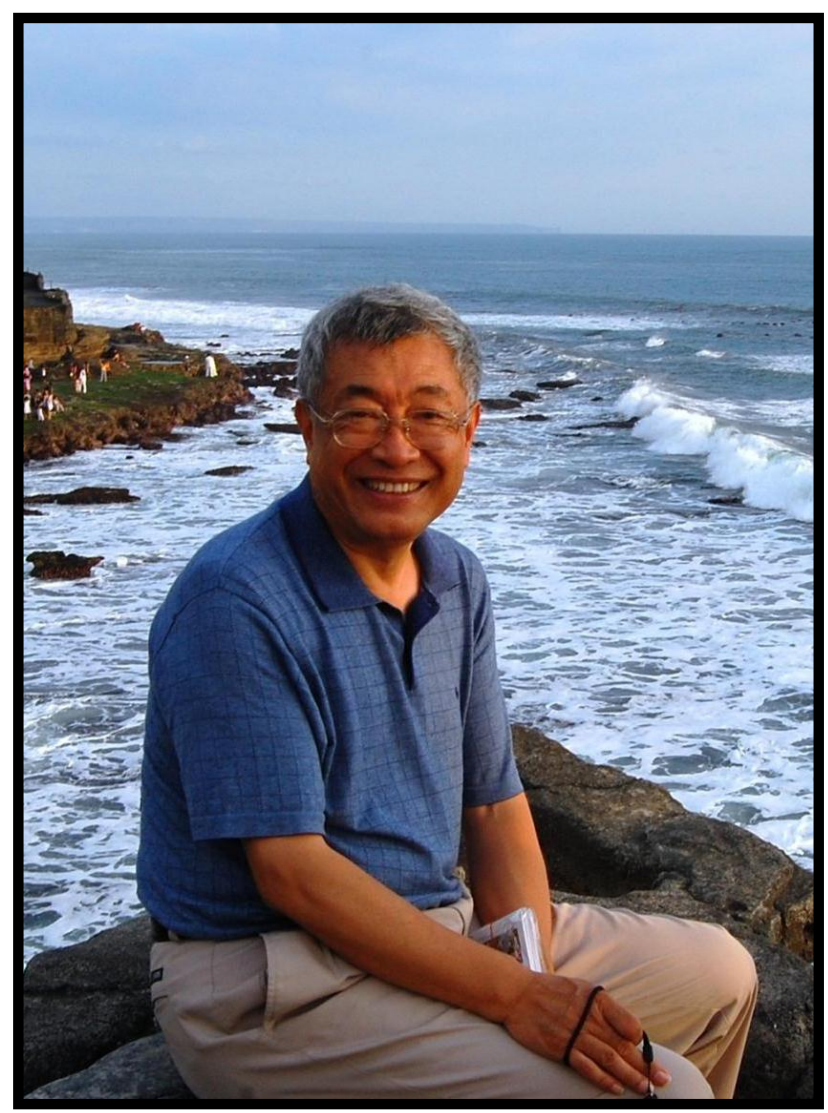

This issue is dedicated to the memory and honor of Professor Zhu Mingyuan, late professor in the First Institute of Oceanography, State Oceanic Administration (SOA). Professor Zhu worked at SOA since 1977, and his broad expertise covered marine pigments, primary productivity, harmful algal blooms, coastal eutrophication, ecosystem dynamics and marine ecosystem management. He was the Co-PI of the 973 project "Ecology and Oceanography of Harmful Algal Blooms in China (CEOHAB I)", and scientific advisor of CEOHAB II. Professor Zhu, a leader in work on the subjects included in this Dedicated Issue, was leading editing work on this Issue before he unexpectedly passed away in Canada during the PICES annual conference in 2013. 